\title{
REFLEXIONES SOBRE LA PROFESIÓN, LA DEONTOLOGÍA Y LA ÉTICA'
}

\section{LEONARDO VELARDE DÁVILA}

- Profesor de Diseño Organizacional y Procesos
Área académica de administración, UPC

\begin{abstract}
RESUMEN
En ésta época de intensa tecnología, globalizada competencia y desarrollo de la información, las universidades mantienen la importante responsabilidad de la formación de los futuros profesionales. Por lo tanto, además de enseñarles teorías, técnicas y desarrollar competencias en los estudiantes, es fundamental formarlos y orientarlos en el tema de la Deontología y Ética Profesional, para que los mismos puedan comportarse adecuadamente en diversos escenarios, con evidentes valores éticos e incuestionable solvencia profesional; éste tema es trascendental en éstos difíciles tiempos, para así consolidar la preparación integral de los futuros profesionales, los cuales asumirán la importante gestión de empresas o el país, inclusive.
\end{abstract}

Palabras clave: Deontología, Ética

\section{ABSTRACT}

In these times of intensive use of technology, global competition and information development, universities still hold an essential responsibility in the education of future professionals. Therefore, besides the development of student's skills and competences while teaching them theory and techniques, it is imperative to train them in professional ethics and deontology, so their behavior may be appropriate in different scenarios, showing a clear moral compass along with sound professional fundamentals. This is a crucial issue nowadays, for strengthening the integral education of future professionals, who will be managing and leading not only our companies but our country as well.

\section{Key words: Deontology, Ethics}

Toda formación profesional está compuesta por diversos elementos (por ejemplo, los conocimientos, las técnicas y los valores) que hoy se conocen como la estructura básica de competencias. Por lo tanto, los profesionales de ahora deben tener muy en cuenta la compartida importancia y la aplicación de dichos elementos al ejercer una carrera

1. UPC Review of Global Management, Volumen 3, Número 1, junio 2017 determinada. Al margen del tema punible, al cometerse una falta debe estar siempre presente la reflexión sensata y coherente de lo que representa el accionar profesional. Actualmente, el desarrollo tecnológico hace posible llevar a cabo excelentes avances y trabajos de altísima calidad. Sin embargo, la misma tecnología puede ser empleada para facilitar situaciones dolosas, irregulares y antiéticas en el ejercicio de la profesión. Por ello, es fundamental, desde la cátedra universitaria y en todas las profesiones, insistir en la debida formación deontológica y de ética profesional, para que, de esta manera, se pueda contar no solo con profesionales idóneos y competitivos, sino también con un comportamiento ético en cualquier escenario.

La globalización permite importar y exportar profesionales de diferentes especialidades, pero debe tenerse especial cuidado con su debida formación, experiencia y antecedentes profesionales, para así estar seguros de su total probidad.

Independientemente de ello, es un tema de principios trabajar con una escala o código de valores que transmita confiabilidad, credibilidad y ética profesional, como requisito imprescindible al contratar un profesional local, nacional o extranjero.

La preocupación por la ética, como tema de reflexión, es muy antigua. No obstante, sigue vigente, y a la luz de la realidad es indispensable en toda sociedad. Es esencial formar profesionales con alta competitividad, pero es igualmente determinante hacerlo con una indiscutible calidad personal, humana y ética, en cualquier situación o circunstancia.

En estos tiempos, existe una crisis de valores en personas e instituciones. Es muy preocupante que se tengan que invertir altos presupuestos en investigaciones, contralorías y seguimiento para evitar la corrupción o luchar contra ella, cuando dicha inversión podría ser mejor aprovechada en proyectos de infraestructura, como escuelas, hospitales, carreteras y saneamiento básico, entre otras obras que el país requiere de una manera urgente.

El tema es alarmante, ya que abarca instituciones públicas y privadas no solo nacionales, sino también extranjeras, lo cual ahonda más la problemática sobre la falta de ética y demás valores al asumir un cargo o desarrollar una profesión. En este contexto, la enseñanza y práctica de la deontología y la ética profesional es prioritaria; debe 
ser permanente y de un análisis crítico. Los nuevos profesionales, al margen de la especialidad de la que provengan, han de poseer comportamientos, actitudes y valores éticos de manera inherente, contar con civismo y ser probos. Están obligados a saber la diferencia entre lo que es correcto, justo y lícito y lo que es incorrecto, injusto e ilícito.

Ser profesional tiene un gran significado. La frase "A nombre de la nación", que suele redactarse en los diplomas de los títulos profesionales, lo explica todo. Por tal consideración, es indispensable formar en las universidades a profesionales con una visión ética sólida, así como con un modo de actuar transparente y un compromiso social inquebrantable, con su país y con las instituciones que lo comprenden. No puede haber desarrollo profesional sin una base moral y ética.

Cuando somos gerentes profesionales, con el título profesional mencionado, y administramos una empresa privada o una institución pública, es fundamental asumir un compromiso social con todos los grupos de interés, para así desarrollar una gestión transparente, eficaz y de alto contenido ético. Ello debería tener como propósito asignar la confianza en los profesionales calificados moral y técnicamente, cuyos resultados de gestión explicarán éxitos con ética y deontología profesional.

Siguiendo con el enfoque de administración, debemos iniciar por "administrarnos a nosotros mismos". Este es el punto de partida antes de administrar a otras personas y organizaciones. Administrarse uno mismo conlleva, como punto indispensable, incluir patrones de comportamiento ético y moral en todo instante. Todos nuestros actos deben estar respaldados por dicho comportamiento ético y ser decididos, de una manera libre y voluntaria, sobre la base de una clara convicción.

Debemos complementar esa misma arista de administrarse uno mismo con la famosa matriz de coherencia entre lo que pensamos, hablamos y hacemos. Es decir, en toda persona, y especialmente en todo profesional, deben conjugarse armoniosamente y ser coherentes el pensamiento, la palabra y la acción. En consecuencia, la aplicación de dicha matriz es esencial en todo ejercicio profesional, acorde con la referida deontología y ética profesional.

El mundo evoluciona intensa y raudamente, y se orienta hacia lo externo, olvidando frecuentemente el lado interno de las personas. En tal virtud, obtener una profesión nos debe llevar a mejorar y a enriquecer, primero, ese aspecto interno, para ser mejores personas y, luego, mejores profesionales para la sociedad. Esto es vital, y debe nacer del seno familiar: es una responsabilidad básica e ineludible de toda familia, dentro del contexto social correspondiente.

Las universidades muestran un gran interés en formar profesionales completos. Sin embargo, ayudaría mucho que los estudiantes que ingresan cuenten con valores éticos cultivados en el hogar, pues esto facilitaría el trabajo en el claustro universitario. Ello no significa que se dejen de atender aquellos casos con ausencia de valores o, incluso, con antivalores éticos, pero debe quedar claro que esta no es la principal responsabilidad de la universidad. Repetimos que es la familia, como base de la sociedad, la que debe cumplir su rol formativo y ético del futuro ciudadano y profesional; es el inicio trascendental.

Subrayamos el hecho de plantearnos objetivos y metas altas para un progreso mayor, pero también debemos tomar en cuenta retos o desafíos como el que nos ocupa, para una eficaz y eficiente administración de las organizaciones públicas y privadas. Para crecer como país, antes hemos de crecer como profesionales. Lo que significa desarrollarnos, paralelamente, como personas y como integrantes de una sociedad que debería y tiene que esperar lo mejor de cada uno de nosotros.

Las personas pasamos y quedan las instituciones: dejemos un legado positivo a las siguientes generaciones aplicando gerencia con valores éticos, transparencia de gestión y creación de valor, y, especialmente, con la amplia satisfacción de nuestros proveedores y consumidores. Y de igual modo con competidores, público en general y autoridades del Estado, de forma que se integren la eficacia administrativa y el progreso institucional, así como la sostenibilidad y la calidad personal como ética de sus trabajadores, y muy especialmente de sus gerentes y profesionales.

Por lo expuesto, es preciso el aporte del sistema educativo en todos sus niveles, para poder remediar esta álgida problemática, al igual que retomar, robustecer o afianzar los valores éticos en toda actividad educativa, conjuntamente con el accionar de las familias y de la sociedad civil.

Con la evolución de la ciencia y la tecnología, se están resolviendo varios problemas y se está creando confort de una forma que no tiene precedentes. No obstante, se descuida la parte interior o cualitativa de las personas; es decir, su calidad humana y, sobre todo, los principios y valores éticos básicos (por ejemplo, la responsabilidad, el respeto y la solidaridad).

Desde las perspectivas empresarial, gerencial o administrativa, cada organización posee en su cultura dichos valores (generalmente, un decálogo) para orientar el comportamiento interno y externo de la compañía, lo cual promueve una mejor relación con sus grupos de interés dentro del enfoque sistémico y holístico.

Si aplicamos la administración por valores, se refuerzan más la importancia y los beneficios de la aplicación de dichos valores en la gestión empresarial, además de su adecuado vínculo con todos los actores o grupos de interés. Y no solo en las relaciones comerciales o de negocios, sino en campañas de ayuda, alianzas estratégicas y planes de responsabilidad social empresarial, así como en proyección a la comunidad y programas de voluntariados, entre otros aspectos. Por todas estas consideraciones, los valores éticos son ejes sumamente trascendentales para nuestro comportamiento y para las relaciones humanas con todos los públicos, todo lo cual nos lleva a valorar justamente la importancia de actuar de buena fe, con principios y ética con todos los que nos relacionamos diariamente y en la gestión cotidiana de la empresa, hacia al interior y el exterior. 
Retornando al tema de la deontología profesional, es incuestionable la conveniencia de su enseñanza y aplicación respectiva, en todas las profesiones, de modo que luego podamos cumplir cabal y satisfactoriamente nuestras funciones profesionales, para las cuales hemos sido formados desde la universidad. Por lo tanto, allí existe un compromiso a priori de los claustros universitarios. Lo importante es que dicha asignatura se enseñe de una manera teórica y práctica, con casos aplicativos, talleres y análisis de situaciones diversas que enfrentamos diariamente, y que nos ayude a estar mejor preparados para brindar un eficiente servicio profesional.

Por otro lado, la ética profesional complementa la forma correcta de comportarnos con nuestra profesión. Es lo que debemos y no debemos hacer, en el marco de mencionados valores éticos. Es un tema crucial en las organizaciones, puesto que a veces nos orientamos enfáticamente hacia temas relacionados con las ventas, las utilidades o la productividad, y soslayamos los valores éticos en nuestra búsqueda de dichas ganancias o beneficios, y de la propia creación de valor.

El mundo actual nos lleva a reconocer problemas serios de nepotismo, conflictos de intereses, corrupción, tráfico de influencias, negocios ilícitos y otras manifestaciones carentes de toda ética profesional, lo cual afecta a los mercados y a toda sociedad, pues acarrea una serie de secuelas negativas para lograr una convivencia adecuada y sentir bienestar, dos elementos fundamentales que toda población aspira a mejorar cada vez más.

En lo que concierne a la profesión, ella es la herramienta, el rol y la acreditación que nos compromete a brindar un adecuado servicio a la sociedad en la que vivimos. No olvidemos que ser profesionales reconocidos y avalados por un título profesional a nombre de la nación, por un lado nos posibilita un medio de vida, pero también subraya el hecho de que, al ser profesionales, adquirimos un compromiso perenne con la sociedad, con nuestro país y su real desarrollo. Al ejercer la profesión, debemos identificar, analizar y resolver problemáticas de nuestra realidad. De igual manera, hay que investigar e innovar permanentemente en la misma.

Con este marco, es posible conjugar una misma visión ética y deontológica en cuanto a las empresas, el Estado y las universidades. Es importante crear un trabajo conjunto, articulando formación profesional y ética debida para las empresas que tenemos y proyectamos, así como en función de los planes de desarrollo del país. El enfoque sistémico y holístico es indispensable aquí, para así trabajar de modo coordinado y hacia una misma visión de país.

Todos los profesionales debemos sumar capacidades, voluntades y calidades para mejorar el nivel de desarrollo nacional de competitividad. Y a ello debe añadirse, además, el factor ético y moral con que todo buen profesional ha de contar. La planificación estratégica del país indica que experimentamos muchas dificultades, retos y problemas nacionales, pero también poseemos una gran cantidad de profesionales idóneos y éticos, que pueden coadyuvar a resolver la mencionada problemática nacional en los diferentes sectores.

Si queremos ser más específicos, busquemos un concepto básico de planificación dual: un plan anual de emergencia y un programa estratégico a mediano y largo plazo, en que la planificación sea sostenible y, a la vez, flexible a los cambios; es decir, se pueden cambiar algunas estrategias y prioridades, pero no los objetivos ni la visión de una planificación global que el país requiere. En ello también están contenidos los temas de profesión, deontología y ética profesional.

De lo anterior, no basta con esmerar la planificación: se deben optimizar la propia ejecución, el control y la evaluación de dichos planes de emergencia y estratégicos. A más de ello, debe existir un compromiso e involucramiento auténtico (nuevamente, son valores éticos) de los profesionales con dicha planificación, de manera que podamos avistar un mejor futuro, lo cual significa trascender con la gestión, trascender con nuestra profesión y, se reitera, dejar un legado positivo para las siguientes generaciones de peruanos.

Cualquier plan de desarrollo del país debe iniciarse en los valores o pilares éticos, que han de cumplirse debidamente ante cualquier dificultad, amenaza o peligro. Por todo lo explicado, esta reflexión condensa la relevancia de formar desde la cátedra a los futuros profesionales que el país necesita: competitivos, modernos y éticos en todo momento. Las organizaciones son impulsadas por personas, líderes y gerentes, así como por empresarios y dirigentes. Son ellos quienes hacen la gran diferencia de la gestión pública o privada en los variados contextos locales, nacionales e internacionales.

Cuando se trata de evaluar resultados empresariales o de gestión, hay que partir de que los artífices de ello son las personas, con su talento humano, su capital intelectual y su fuerza laboral, o al desarrollar equipos de alto rendimiento. $\mathrm{Y}$, al analizar a dichas personas, debemos ubicar y reconocer sus competencias en conocimientos, técnicas y valores, todo lo cual ha de ser armónico y consistente.

\section{CONCLUSIONES}

Este artículo pretende compartir e ilustrar la responsabilidad, el compromiso y la ética que todo profesional actual o futuro debe tener para mejorar nuestra sociedad, de modo que todos podamos conjugar una unidad de criterios y esfuerzos multidisciplinarios para afrontar y resolver nuestras problemáticas, y proyectar la visión de un mejor país, propósito que podemos conseguir en función de la calidad profesional, personal y ética.

La idea de ponerse de acuerdo todos los profesionales, o la gran mayoría de ellos, aunque es compleja, no resulta imposible. Hay que buscar los puntos comunes y las disposiciones correspondientes. El segmento profesional debe ser protagonista de los grandes cambios que el Perú 
requiere; a priori, debe unificar criterios y compromisos, y sumar esfuerzos para lograr los grandes propósitos nacionales, como se indicó en párrafos precedentes.

Los que tenemos varias décadas de vida y de ejercicio profesional sabemos que la profesión nos permite contar con una herramienta muy valiosa para nosotros mismos y nuestras familias, $y$, especialmente, para nuestro país. Podemos trabajar directamente en la solución de los problemas nacionales, reiteramos, en base previa e indispensable de la aplicación sostenible de compromisos éticos, morales y deontológicos, desde cada profesión. Una primera idea puede ser la concertación técnica y operativa de colegios profesionales, universidades, empresarios y el propio Estado.

Se puede esgrimir que es hora de optimizar o de innovar la calidad profesional y ética en la formación de todos los profesionales, lo cual responde a estar mejor preparados y unidos para enfrentar y superar los grandes problemas nacionales, partiendo de consolidar los grandes valores éticos: responsabilidad, compromiso y respeto, así como la transparencia y la vocación de servicio, entre otros.

Todo lo aquí señalado es visto bajo una arista profesional, técnica y académica, y busca los mejores caminos y destinos para el Perú, con base en sus profesionales, quienes pueden ser muy capaces de lograr grandes objetivos y metas, con entrega genuina a lo que el país necesita actualmente; $\mathrm{y}$, además, de proyectarlo a una actitud proactiva, que incluya elaborar proyectos, innovar y generar cambios para evolucionar.

Quienes somos docentes tenemos un doble compromiso: primero, como profesionales, y segundo, como artífices en la adecuada formación de futuros profesionales dotados de conocimientos, competencias y valores. Dicho rol formativo y académico debe lograr aprendizajes significativos, profundos y colaborativos. Esta formación, además, debe incluir la innovación constante, que resulta indispensable en estos tiempos para mantenerse competitivos y con alta empleabilidad. Ella ha de ser el elemento protagonista de la cultura actual, de toda organización moderna y que desea mantenerse vigente, pero sin prescindir nunca de la deontología y la ética profesional de todos sus colaboradores.

Al finalizar, subrayamos lo siguiente: "Indiscutiblemente, la mejor inversión que puede hacer una persona, empresa o país es en educación", reflexión que ratifica la intrínseca y extrínseca importancia de la educación en el desarrollo y la evolución de una nación, así como en sus organizaciones y sus ciudadanos. 